\title{
ABORDAGEM ERGONÔMICA PARA A AVALIAÇÃO DE INTERAÇÃO NA INFOGRAFIA JORNALÍSTICA
}

\section{ERGONOMIC APPROACH FOR EVALUATION OF INTERACTION IN ONLINE JOURNALISTIC INFOGRAPHICS}

\author{
Rafael de Castro Andrade ${ }^{1}$, M. e. \\ (1) Universidade Federal do Paraná \\ e-mail:ancara@gmail.com
}

Infografia, análise ergonômica, interação

Recursos interativos são amplamente utilizados em infográficos jornalísticos na internet, no entanto a utilização destes recursos sem um planejamento adequado pode comprometer a compreensão do conteúdo. Neste sentido, o presente artigo busca estruturar um procedimento de análise da interação de infográficos pautado em critérios ergonômicos para possibilitar a identificação de deficiências da interação.

\section{Infographics, ergonomic evaluation, interaction}

Interactive features are widely used in journalistic infographics on the web. However, using these resources without proper planning can compromise the content understanding. Therefore, this article seeks to build a procedure of interaction analysis of infographics based on ergonomic criteria for identify deficiencies on interaction.

\section{Introdução}

A infografia pode ser compreendida como uma forma de representação visual de informações, a qual sob a perspectiva da linguagem gráfica (TWYMAN, 1985) combina os diferentes modos de simbolização da linguagem gráfica: verbal, pictórico e esquemático para explicar ou informar algo (LIMA, 2015). Em um infográfico é possível encontrar ilustrações, mapas, diagramas e outras estruturas visuais explicativas, as quais Sancho (2001) denomina como infogramas. Para Fassina (2011) estas unidades não devem ser desassociadas, isto é, se tiradas do contexto do infográfico estas subpartes perdem sua eficácia comunicacional afetando a compreensão do infográfico como um todo.

Os infográficos são comuns nos veículos jornalísticos, onde ajudam os leitores a compreender assuntos complexos, os quais seriam difíceis de explicar de outra forma (LIMA, 2015). Com a expansão destes veículos para a internet os infográficos vislumbraram novas possibilidades, como o uso de recursos interativos e animados. Neste contexto digital é possível identificar três formatos básicos de infográficos: 


\section{$16^{\circ}$ \\ ERGODESIGN USIHC CINAHPA}

Estáticos: infográficos que se apresentam como uma imagem estática, podendo ser uma mimese de infográficos impressos;

Animados: infográficos que apresentam imagens em série "que modificam sua estrutura visual ao longo do tempo, simulando mudança através da percepção do observador." (MIRANDA, 2013)

Interativos: Infográficos que possuem elementos de interação, permitindo alguma ação por parte do usuário.

Para Lankow et al. (2012) a interação na infografia pode ter diversas funções, como: encorajar a exploração do conteúdo, guiar a narrativa ou ainda ajudar a superar limitações do suporte como controles de passos que evitem longas barras de rolagem na tela.

Apesar dos aspectos positivos da interação na infografia, estudos anteriores (ANDRADE, 2014) indicam que a simples adição destes recursos podem comprometer a compreensão do conteúdo. Além de agravar deficiências existentes na apresentação gráfica de informações dos infográficos.

Neste sentido, são escassos os estudos os quais forneçam instrumentos de avaliação ou recomendações para o uso de interação em infográficos. Sendo assim, o presente artigo busca propor um procedimento para avaliar critérios ergonômicos do uso de interação em infográficos baseado nos aspectos da interação na infografia levantados por Miranda (2013) e nos critérios de avaliação ergonômica de interfaces levantados por Bastien \& Scapin (1993).

\section{Aspectos da interação na infografia}

A literatura trata a interação na infografia sob três aspectos principais, estrutura, estilo e objetos de interação. Para Cairo (2013) a interação deve possibilitar a imersão do usuário no conteúdo por meio de estruturas de navegação, as quais podem ser categorizadas de duas formas: $16^{\circ}$ Ergodesign - Congresso Internacional de Ergonomia e Usabilidade de Interfaces Humano Tecnológica: Produto, Informações Ambientes Construídos e Transporte

$16^{\circ}$ USIHC - Congresso Internacional de Ergonomia e Usabilidade de Interfaces Humano Computador

CINAHPA | 2017 - Congresso Internacional de Ambientes Hipermídia para Aprendizagem.
Lineares: onde a estrutura do infográfico é disposta como em uma apresentação de slides, sendo que a interação permite ir para a próxima etapa. Para compreender a narrativa do infográfico é necessário ter visto o passo anterior;

Multi-lineares: possuem uma estrutura onde os conteúdos independem de sequência, permitindo que o usuário crie sua própria lógica de navegação.

Além da estrutura o autor também relaciona quatro estilos de interação (CAIRO 2008, 2016) baseado nos estudos de Preece et al. (2005). Os estilos são os seguintes:

Instrução - No qual o usuário por meio de instruções simples interage com a interface, como ao clicar em um botão ou item.

Conversação - Possibilita ao usuário um diálogo real com o infográfico, onde o usuário adiciona dados ou parâmetros que provocam alterações no infográfico.

Manipulação - Quando a interface permite que o usuário manipule atributos físicos de objetos, por exemplo: arrastar um objeto para mudar de posição ou tamanho.

Exploração - Segundo o autor seria a possibilidade de explorar livremente informações na interface, assemelhando-se a um jogo de vídeo game em primeira pessoa. No entanto o próprio autor indica que isto é raramente visto na infografia dado o alto custo de produção.

Por fim, o último aspecto da interação encontrado na literatura trata dos pontos do infográfico onde ocorrem as interações. Para Miranda (2013) estes podem ser denominados como objetos de interação, os principais listados pelo autor são: 


\section{$16^{\circ}$ \\ ERGODESIGN USIHC CINAHPA}

$16^{\circ}$ Ergodesign - Congresso Internacional de Ergonomia e Usabilidade de Interfaces Humano Tecnológica: Produto, Informações Ambientes Construídos e Transporte

$16^{\circ}$ USIHC - Congresso Internacional de Ergonomia e Usabilidade de Interfaces Humano Computador

CINAHPA | 2017 - Congresso Internacional de Ambientes Hipermídia para Aprendizagem.
1. Controles de narrativa linear - compostos por botões de avançar e voltar;

2. Controles de seleção de conteúdo - composto por barras de menu (CYBIS et al., 2007), formados por botões, abas e links;

3. Controles de andamento - controles encontrados em reprodutores de vídeos (e.g. Youtube entre outros), compostos de botões de início/pausa; barra de andamento; botões de avançar/retroceder; e controles de áudio;

4. Barra de rolagem - a visualização é condicionada ao tamanho da tela, neste sentido as barras de rolagem auxiliam a navegar por interfaces que ocupam um espaço maior que a tela;

5. Controles de zoom - o princípio do zoom consiste em ampliar ou diminuir determinado ponto de uma imagem, este tipo de controle é comum em mapas (e.g Google maps);

6. Objetos sensíveis ao passar do mouse objetos gráficos que apresentam mudanças perceptíveis na interface ao passar o cursor do mouse sobre;

7. Objetos sensíveis ao clique do mouse - as mudanças na interface se tornam perceptíveis apenas ao clique;

8. Objetos manipuláveis - permite mover ou arrastar um objeto gráfico com o mouse para visualizar diferentes vistas deste objeto.

\section{Critérios ergonômicos para análise de interfaces}

Os pesquisadores Bastien \& Scapin (1993) em seu trabalho seminal intitulado 'Ergonomic Criteria for the Evaluation of Human-Computer Interfaces 'levantam uma série de critérios para análise ergonômica de interfaces os quais têm sido utilizados extensamente por diversos pesquisadores. Segundo Freire Junior (2010) o modelo proposto pelos autores funciona "como uma ferramenta padronizada que auxilia no juízo crítico quanto as 'qualidades ergonômicas' das interfaces desenvolvidas para sistemas informatizados. " (FREIRE JUNIOR, 2010 p.7). Os critérios desenvolvidos pelos autores são amplos e permitem a análise de diversos tipos de interfaces interativas. De forma resumida os critérios levantados são:

\section{Orientação}

Relativo a como a interface orienta o usuário no sistema e engloba os seguintes subcritérios:

- Aconselhamento (prompting);

- Agrupamento / Distinção de itens por formato e por posição espacial;

- Feedback imediato.

\section{Carga de trabalho}

Relativo ao papel que os elementos da interface desempenham reduzindo a carga cognitiva e perceptual e engloba os seguintes subcritérios:

- Brevidade;

- Concisão;

- Ações mínimas;

- Densidade da informação.

\section{Controle explícito}

Está ligado as ações do usuário e atende os seguintes subcritérios:

- Ações explícitas;

- Controle do usuário.

\section{Adaptabilidade}

Capacidade de se adaptar ao contexto e as necessidades do usuário oferecendo os seguintes subcritérios:

- Flexibilidade;

- Nível de experiência do usuário. 


\section{$16^{\circ}$ \\ ERGODESIGN USIHC CINAHPA}

\section{Gerenciamento de erros}

Refere-se a capacidade da interface de prevenir erros e permitir o usuário contorná-los e possuem os seguintes subcritérios:

- Proteção contra erros;

- Qualidade das mensagens de erro;

- Correção de erros.

\section{Consistência}

A consistência refere-se à coerência da interação ao longo do projeto, por exemplo manter a mesma função para um mesmo tipo de botão ao longo das páginas de um site.

\section{Significado dos códigos e denominações}

Está ligado ao relacionamento semântico entre os códigos, itens e ações as quais se referem.

\section{Compatibilidade}

Refere-se à correspondência entre as necessidades e expectativas do usuário com as características do sistema.

\section{Procedimento de análise ergonômica de infográficos}

Com base nos aspectos apresentados anteriormente e no trabalho de Santos et al. (2015) foi adaptado um protocolo (Tabela 1), no qual estão dispostos elementos relativos a interação do infográfico como: estrutura, estilo de interação e objetos de interação. O objetivo deste protocolo é identificar os principais aspectos da interação no infográfico.

Tabela 1 - Protocolo 1 , relativo a estrutura, estilo e objetos de interação

\begin{tabular}{l|l} 
Estrutura & \\
\hline Linear & \\
\hline Multilinear & \\
\hline
\end{tabular}

$16^{\circ}$ Ergodesign - Congresso Internacional de Ergonomia e Usabilidade de Interfaces Humano Tecnológica: Produto, Informações Ambientes Construídos e Transporte

$16^{\circ}$ USIHC - Congresso Internacional de Ergonomia e Usabilidade de Interfaces Humano Computador

CINAHPA | 2017 - Congresso Internacional de Ambientes Hipermídia para Aprendizagem.

\begin{tabular}{l:l} 
Estilo de interação \\
\hline Instrução & \\
\hline Conversação & \\
\hline Manipulação & \\
\hline Exploração &
\end{tabular}

\begin{tabular}{l:l} 
Objetos de Interação \\
\hline $\begin{array}{l}\text { Controles de } \\
\text { narrativa }\end{array}$ & \\
linear & \\
\hline $\begin{array}{l}\text { Controles de } \\
\text { seleção de } \\
\text { conteúdo }\end{array}$ & \\
\hline $\begin{array}{l}\text { Controles de } \\
\text { andamento }\end{array}$ & \\
\hline $\begin{array}{l}\text { Barra de } \\
\text { rolagem }\end{array}$ & \\
\hline $\begin{array}{l}\text { Controles de } \\
\text { zoom }\end{array}$ & \\
\hline $\begin{array}{l}\text { Objetos } \\
\text { sensíveis ao } \\
\text { passar do } \\
\text { mouse }\end{array}$ & \\
\hline $\begin{array}{l}\text { Objetos } \\
\text { sensíveis ao } \\
\text { clique do } \\
\text { mouse }\end{array}$ & \\
\hline $\begin{array}{l}\text { Objetos } \\
\text { manipuláveis }\end{array}$ & \\
\hline
\end{tabular}

Posteriormente, os dados coletados por este protocolo são submetidos a avaliação de um check-list onde estão listados os critérios de Bastien \& Scapin (1993). Desta forma, são relacionados os impactos destes dados em cada um dos critérios estabelecidos pelos autores, assim é possível identificar itens em desacordo e possíveis deficiências da interação.

Para explorar as possibilidades do procedimento foi realizada uma análise que pode ser observada a seguir.

\subsection{Análise ergonômica do infográfico}

O procedimento de análise foi aplicado ao infográfico "Rio 2016 - O legado Olímpico" (Figura 1). Este infográfico foi escolhido por ser publicado por um jornal de grande circulação o 


\section{$16^{\circ}$ \\ ERGODESIGN USIHC CINAHPA}

Estado de São Paulo (Estadão) e também por se tratar de uma publicação recente a época do presente artigo. Os resultados da análise são apresentados a seguir.

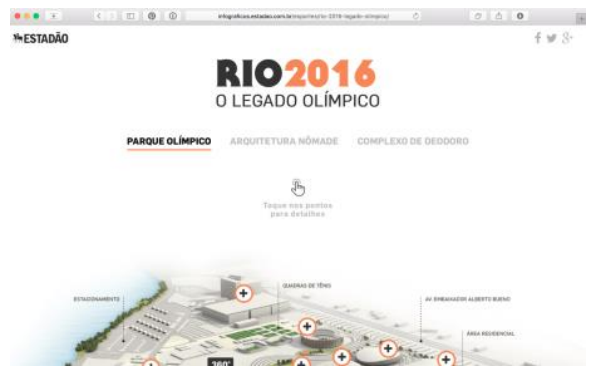

Figura 1 - Tela incial do infográfico (http://infograficos.estadao.com.br/esportes/rio-2016-legado-olimpico/)

\section{Estrutura}

Em relação a estrutura o infográfico apresenta uma estrutura multilinear. Isto é facilmente identificado pelo controle de seleção de conteúdo (Figura 2), o qual permite o usuário definir sua estratégia de navegação entre as três telas do infográfico.

\section{PARQUE OLIMPICO ARQUITETURA NÔMADE COMPLEXO DE DEODORO}

Figura 2 - Controle de seleção de conteúdo

\section{Tipo de Interação}

O tipo de interação predominante no infográfico é de instrução, onde o usuário clica em um botão ou link para obter uma ação do infográfico. No entanto, algumas disponibilizam um recurso o qual permite uma manipulação da imagem, onde esta revela o antes e o depois (Figura 3).

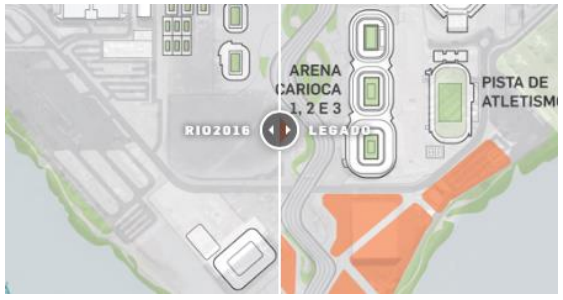

Figura 3 - Detalhe do elemento que permite a manipulação $16^{\circ}$ Ergodesign - Congresso Internacional de Ergonomia e Usabilidade de Interfaces Humano Tecnológica: Produto, Informações Ambientes Construídos e Transporte

$16^{\circ}$ USIHC - Congresso Internacional de Ergonomia e Usabilidade de Interfaces Humano Computador

CINAHPA | 2017 - Congresso Internacional de Ambientes Hipermídia para Aprendizagem.

\section{Objetos de interação}

No infográfico é possível observar uma predominância de objetos de interação como objetos sensíveis, ao passar do mouse e ao clique do mouse (Figura 4), além do uso da barra de rolagem do próprio browser.

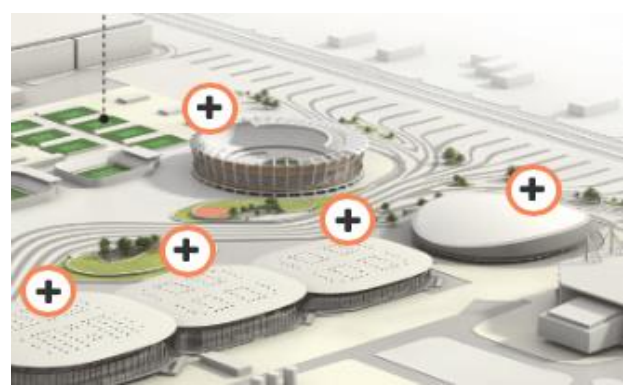

Figura 4 - Detalhe do elemento dos objetos sensíveis ao passar e ao clique do mouse

Em menor número também são encontrados controles de andamento, nos vídeos incorporados no infográfico. Apesar do infográfico apresentar diversos mapas, não foi utilizado o recurso de zoom. Na tabela 2 é possível ver em detalhe as ocorrências dos objetos de interação no infográfico.

Tabela 2 - Objetos de interação presentes no infográfico

\begin{tabular}{|c|c|}
\hline $\begin{array}{l}\text { Objeto de } \\
\text { Interação }\end{array}$ & Ocorrência no infográfico analisado \\
\hline $\begin{array}{l}\text { Controles de } \\
\text { narrativa linear }\end{array}$ & Não possui \\
\hline $\begin{array}{l}\text { Controles de } \\
\text { seleção de } \\
\text { conteúdo }\end{array}$ & $\begin{array}{l}\text { Menu que permite escolher entre os três } \\
\text { tópicos principais do infográfico }\end{array}$ \\
\hline $\begin{array}{l}\text { Controles de } \\
\text { andamento }\end{array}$ & $\begin{array}{l}\text { Possui nos vídeos, que são vídeos } \\
\text { incorporados de serviços de streaming de } \\
\text { vídeo (YouTube) }\end{array}$ \\
\hline Barra de rolagem & $\begin{array}{l}\text { Utiliza a barra de rolagem do browser no } \\
\text { sentido vertical em todas as seçôes }\end{array}$ \\
\hline $\begin{array}{l}\text { Controles de } \\
\text { zoom }\end{array}$ & Apesar de apresentar mapas não possui \\
\hline $\begin{array}{l}\text { Objetos sensíveis } \\
\text { ao passar do } \\
\text { mouse }\end{array}$ & $\begin{array}{l}\text { Possui nos itens para indicar que são } \\
\text { clicáveis }\end{array}$ \\
\hline $\begin{array}{l}\text { Objetos sensíveis } \\
\text { ao clique do } \\
\text { mouse }\end{array}$ & $\begin{array}{l}\text { A maioria dos itens de interação do } \\
\text { infográfico são deste tipo }\end{array}$ \\
\hline $\begin{array}{l}\text { Objetos } \\
\text { manipuláveis }\end{array}$ & $\begin{array}{l}\text { Em algumas imagens, existe um recurso de } \\
\text { arrastar para revelar antes/depois }\end{array}$ \\
\hline
\end{tabular}

Realização:

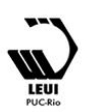




\section{$16^{\circ}$ \\ ERGODESIGN USIHC CINAHPA}

Estes dados agora são discutidos a luz do checklist. Para um maior detalhamento os itens serão expostos a seguir por critérios.

\section{Orientação}

Foram encontradas dificuldades em relação a forma que o infográfico orienta o usuário a utilizálo. Apenas na primeira tela tem uma breve instrução (Figura 5) de como utilizar um mapa principal. No entanto, devido a sua estrutura multilinear, talvez seja necessário por parte do usuário um maior esforço para descobrir como interagir com as diversas unidades do infográfico, como por exemplo, o elemento de manipulação já apresentado na Figura 3 exige uma nova maneira de interagir com o infográfico que não é informada.

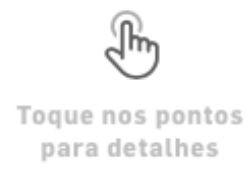

Figura 5 - Detalhe da instrução de como usar a interface.

Outra questão identificada tange ao quesito legibilidade, em diversas partes do infográfico há tipografias com uma tonalidade muito próxima do fundo, o que dificulta a leitura (Figura 6).

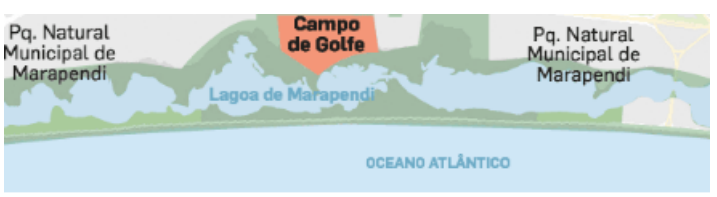

\section{Depois de 112 anos, o golfe volta à Olimpíada e já tem lugar assegurado entre as principais polêmicas dos Jogos de 2016. Tudo por causa da decisão da}

Figura 6 - Detalhe da cor da tipografia. $16^{\circ}$ Ergodesign - Congresso Internacional de Ergonomia e Usabilidade de Interfaces Humano Tecnológica: Produto, Informações Ambientes Construídos e Transporte

$16^{\circ}$ USIHC - Congresso Internacional de Ergonomia e Usabilidade de Interfaces Humano Computador

CINAHPA | 2017 - Congresso Internacional de Ambientes Hipermídia para Aprendizagem.

Tabela 3 - Critérios e subcritérios relativos a orientação

\begin{tabular}{cll}
\hline Orientação & $\begin{array}{l}\text { Aconselhamento } \\
\text { (prompting) }\end{array}$ & $\begin{array}{l}\text { Apenas na primeira tela } \\
\text { há uma instrução de uso }\end{array}$ \\
\cline { 2 - 3 } & $\begin{array}{l}\text { Agrupamento / } \\
\text { Distinção de } \\
\text { Itens (Formato e } \\
\text { Localização) }\end{array}$ & $\begin{array}{l}\text { Os grupos e os itens são } \\
\text { claros e facilmente } \\
\text { distinguíveis }\end{array}$ \\
& $\begin{array}{l}\text { Feedback } \\
\text { Imediato }\end{array}$ & $\begin{array}{l}\text { O infográfico responde a } \\
\text { todas ações } \\
\text { imediatamente }\end{array}$ \\
& $\begin{array}{l}\text { As tipografias têm um } \\
\text { bom tamanho de letra, no } \\
\text { entanto o contraste com o } \\
\text { fundo não é ideal }\end{array}$ \\
\hline
\end{tabular}

\section{Carga de trabalho}

Acredita-se que o estilo de interação de instrução, por ter uma característica mais simples, contribui para este critério, uma vez que as interações são simples possibilitam o usuário intuir facilmente alguns usos. No entanto, foram encontradas dificuldades em relação a brevidade e ações mínimas, devido as barras de rolagem. As longas rolagens nas páginas dificultam encontrar a informação ou navegar por todo o infográfico. A avaliação completa pode ser vista na Tabela 4

Tabela 4 - Critérios e subcritérios relativos a carga de trabalho

\begin{tabular}{cll}
\hline $\begin{array}{l}\text { Carga de } \\
\text { Trabalho }\end{array}$ & Brevidade & $\begin{array}{l}\text { É afetada pelo uso da } \\
\text { barra de rolagem como } \\
\text { única forma de } \\
\text { navegação }\end{array}$ \\
\cline { 2 - 3 } & Concisão & $\begin{array}{l}\text { É atendido, devido as } \\
\text { interações serem } \\
\text { simplificadas em sua } \\
\text { maioria. }\end{array}$ \\
\cline { 2 - 3 } & Ações mínimas & $\begin{array}{l}\text { A rolagem é muito grande } \\
\text { em algumas partes. }\end{array}$ \\
& $\begin{array}{l}\text { Densidade de } \\
\text { informação }\end{array}$ & É atendido \\
& &
\end{tabular}

A avaliação completa deste critério pode ser observada na Tabela 3. 


\section{$16^{\circ}$ \\ ERGODESIGN USIHC CINAHPA}

$16^{\circ}$ Ergodesign - Congresso Internacional de Ergonomia e Usabilidade de Interfaces Humano Tecnológica: Produto, Informações Ambientes Construídos e Transporte

$16^{\circ}$ USIHC - Congresso Internacional de Ergonomia e Usabilidade de Interfaces Humano Computador

CINAHPA | 2017 - Congresso Internacional de Ambientes Hipermídia para Aprendizagem.

\section{Controle Explícito}

De forma geral as ações são explícitas na maioria do infográfico, no entanto em alguns pontos não há uma clareza, alguns links apresentam comportamentos diferentes. Como na Figura 7 há um redirecionamento para fora do infográfico, o que não é alertado em nenhum momento, tão pouco é oferecido ao usuário a opção de não ir para a página externa.

\section{ARENA DO FUTURO}

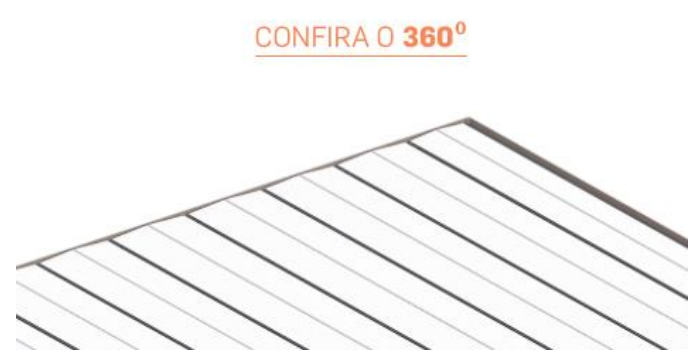

Figura 7 - Detalhe do link que possui comportamento diferente.

Na tabela 5 pode-se observar a avaliação completa deste critério.

Tabela 5 - Critérios e subcritérios relativos ao controle explícito

\begin{tabular}{lll}
$\begin{array}{l}\text { Controle } \\
\text { Explícito }\end{array}$ & Ações explícitas & $\begin{array}{l}\text { Algumas ações não são } \\
\text { explícitas como em } \\
\text { alguns links que } \\
\text { redirecionam para fora } \\
\text { do infográfico }\end{array}$ \\
\cline { 2 - 3 } & $\begin{array}{l}\text { Não oferece a opção ao } \\
\text { usuário de se manter no } \\
\text { infográfico }\end{array}$
\end{tabular}

\section{Adaptabilidade}

O infográfico não apresenta dispositivos que permitam os usuários selecionarem ou adaptarem o mesmo a suas preferências. No entanto, como o estilo de interação é simplificado, acredita-se que este atenda de forma satisfatória tanto usuários experientes e inexperientes. Maiores detalhes deste critério podem ser vistos na tabela 6 .
Tabela 6 - Critérios e subcritérios relativos a adaptabilidade

\begin{tabular}{lll}
$\begin{array}{l}\text { Adapta- } \\
\text { bilidade }\end{array}$ & Flexibilidade & $\begin{array}{l}\text { É limitada, permite ao } \\
\text { usuário apenas a sua } \\
\text { estratégia de qual parte } \\
\text { do infográfico começar a } \\
\text { ler. }\end{array}$ \\
\cline { 2 - 3 } & Experiência do & $\begin{array}{l}\text { Aparentemente está } \\
\text { adaptado para usuários } \\
\text { experientes } \text { e } \\
\text { inexperientes devido ao } \\
\text { estilo de interação mais } \\
\text { simples }\end{array}$ \\
\hline
\end{tabular}

\section{Consistência}

A consistência da interação se mantém ao longo de quase todo o infográfico, exceto em alguns casos, como citado anteriormente, de links que levam para fora do infográfico. Os objetos de interação que disparam estes links são similares aos de outras ações comuns no infográfico que apenas abrem pop-ups.

\section{Significado dos códigos}

O significado dos códigos se mantem em todo o infográfico. Em parte, as características do infográfico de consistência da apresentação visual como hierarquia entre títulos e uso de ícones com mesma unidade visual contribui para o atendimento deste critério.

\section{Gestão de erros e Compatibilidade}

Julgou-se que estes itens não se aplicam a infografia interativa pois de forma geral envolvem uma tarefa específica, o que não é o caso da navegação de um infográfico.

\subsection{Conclusões da análise}

De forma geral, foi possível observar que a estrutura de navegação multilinear pode requerer cuidados especiais com a orientação do usuário no infográfico. Para que este possa usufruir melhor dos recursos interativos este deve poder presumir quais serão os resultados de suas ações. 


\section{$16^{\circ}$ \\ ERGODESIGN USIHC CINAHPA}

Outra questão é relativa ao estilo de interação de instrução, um estilo mais simples, que conta com objetos de interação como controle de narrativa e objetos sensíveis ao mouse. No entanto, apesar de simples este estilo necessita de uma concisão na forma de apresentar a interação para o usuário, os objetos de interação clicáveis devem ser evidentes para não passar desapercebidos.

\section{Considerações Finais e desdobramentos}

A abordagem apresentada neste artigo buscou elencar estudos da literatura sobre infografia que permitissem levantar características da interação em infográficos, as quais foram confrontadas com critérios ergonômicos de interação. Este procedimento busca oferecer novas perspectivas sobre o uso de interação em infográficos. Ao realizar a análise é possível identificar deficiências ergonômicas, o que pode em momentos futuros gerar recomendações e estratégias o que pode ser formatado em um instrumento para a produção de infográficos mais eficientes do ponto de vista ergonômico. No entanto, são notórias algumas limitações deste estudo como a necessidade de uma validação do procedimento em uma amostra maior para evidenciar possíveis fragilidades, bem como um levantamento mais amplo de requisitos.

\section{Bibliografia}

ANDRADE, R. C. Infográficos animados e interativos em saúde: Um estudo sobre a compreensão de notícias. Dissertação (Mestrado em Design). Universidade Federal do Paraná, Curitiba, 2014.

BASTIEN, J. M., \& SCAPIN, D. L. Ergonomic Criteria for the Evaluation of HumanComputer Interfaces, 1993.

\section{CAIRO, A. Infografia 2.0: Visualización} interactiva de información en la prensa .Madrid: Alamut, 2008.

CAIRO, A. The Functional Art: An introduction to information graphics and visualization. Berkeley: New Riders. 2013. $16^{\circ}$ Ergodesign - Congresso Internacional de Ergonomia e Usabilidade de Interfaces Humano Tecnológica: Produto, Informações Ambientes Construídos e Transporte

$16^{\circ}$ USIHC - Congresso Internacional de Ergonomia e Usabilidade de Interfaces Humano Computador

CINAHPA | 2017 - Congresso Internacional de Ambientes Hipermídia para Aprendizagem.

CAIRO, Alberto. The truthful art: Data, charts, and maps for communication. New Riders, 2016.

CYBIS, W.; BERTIOL, A. H.; FAUST, R. Ergonomia e usabilidade: conhecimentos, métodos e aplicações. São Paulo: Novatec Editora, 2007.

FASSINA, U. A infografia como recurso comunicacional no processo de aquisição de informação e compreensão de tipografia. Dissertação (Mestrado em Comunicação Visual) Universidade Estadual de Londrina, Centro de Educação, Comunicação e Artes, Londrina, 2011.

FREIRE JÚNIOR, T. R. Análise ergonômica: avaliação da interface de um aplicativo da justiça federal. iv, 118 f., il. Dissertação (Mestrado em Psicologia)-Universidade de Brasília, Brasília, 2010.

LANKOW, J.; RITCHIE, J.; CROOKS, R Infographics: The power of visual storytelling. John Wiley \& Sons, 2012.

LIMA, R. C. O que é infografia jornalística? Revista InfoDesign v. 12, n. 1: 111-127. 2015.

MIRANDA, F. Animação e interação na infografia jornalística: Uma abordagem do Design da Informação. Dissertação (Mestrado em Design). Universidade Federal do Paraná, Curitiba, 2013.

PREECE, J.; ROGERS, Y.; SHARP, H. Design de interação: além da interação homem computador. Porto Alegre: Bookman. 2005.

SANCHO, J. L. V. La infografía: técnicas, análisis y usos periodísticos. Servei Publicacions, D.L. 2001.

SANTOS, G. M. S.; CAMPELLO, S. B.; COUTINHO, S. G.; Variáveis para análise de infográficos interativos: um estudo descritivo em artefatos educacionais para o ensino médio, p. 230242 . In: Anais do $\mathbf{7}^{\mathbf{0}}$ Congresso Internacional de Design da Informação CIDI 2015. São Paulo: Blucher, 2015. 